\title{
Physical-chemical properties and microstructural characterization of traditional mexican chili (Capsicum annuum L.) powders
}

\author{
Perea-Flores María de J. ${ }^{1}$; Fabela-Morón Miriam . $^{2 *}$; Rayas-Amor Adolfo A. ${ }^{2}$; \\ Pérez-Ruíz Rigoberto V. ${ }^{2}$; Ruíz-Hernández Rafael ${ }^{2}$; Linares-Violante Betzabe ${ }^{3}$; \\ Ortega-Avilés Mayahuel ${ }^{1}$; Barba-Bellettini Marcelo ${ }^{4}$; Pérez-Alonso Cesar ${ }^{3}$ \\ ${ }^{1}$ Centro de Nanociencias y Micro y Nanotecnologías, Instituto Politécnico Nacional, Av. Luis Enrique Erro \\ s/n, Zacatenco, Gustavo A. Madero, Ciudad de México, México, C.P. 07738. \\ ${ }^{2}$ Universidad Autónoma Metropolitana, Unidad Lerma. Departamento de Ciencias de la Alimentación. Av. \\ de las Garzas No. 10, Col. El Panteón, Municipio Lerma de Villada, Estado de México, C.P. 52005. \\ ${ }^{3}$ Universidad Autónoma del Estado de México. Facultad de Química. Paseo Colón esq. Paseo Tollocan s/n, \\ Residencial Colón, Toluca, Estado de México, México. C.P. 50120. \\ ${ }^{4}$ Instituto de Desenvolvimento Rural do Paraná (IDR). Rua da Bandeira, 500 Cabral, Curitiba, Paraná, \\ Brasil. C.P. 80035-270 \\ * Correspondence: mf.fabela@correo.ler.uam.mx, qa.miriamfabela@gmail.com
}

\section{ABSTRACT}

Objective: Evaluate the physical-chemical properties and characterize the microstructure of four varieties of traditional Mexican chili (Capsicum annuum L.) powders: "Arbol", "Guajillo", "Piquin" and "Mole ranchero" (Ancho chili).

Citation: Perea-Flores, M. de J., Fabela-Morón, M. F., Rayas-Amor A. A., Pérez-Ruíz, R. V., Ruíz-Hernández, R., Linares-Violante B., Ortega-Avilés M., Barba-Bellettini M., \& PérezAlonso, C., (2021). Physical-chemical properties and microstructural characterization of traditional mexican chili (Capsicum annuum L.) powders.Agro Productividad. https://doi.org/10.32854/ agrop.v14i9.2145

Editor in Chief: Dr. Jorge Cadena Iñiguez

Received: March 25, 2021. Accepted: August 29, 2021. Published on-line: October 12, 2021

This work is licensed under a Creative Commons Attribution-NonCommercial 4.0 International license.
Design/methodology/approach: Physical-chemical properties of chili powders were evaluated by means of moisture content, particle size, aerated and tapped bulk density, Carr index, Hausner ratio, angle of repose (flow properties), capsaicin, and carotenoids content. Microstructure of samples was characterized by Confocal Laser Scanning Microscopy and Scanning Electron Microscopy. ANOVA analysis and Tukey test were performed to evaluate the significant statistical difference between samples at $95 \%$ of confidence level. Results: "Arbol", "Guajillo", "Piquin" and "Mole Ranchero" chili powders presented a cohesive behavior respect to its flow properties related to aerated and tapped bulk density, angle of repose, Carr Index, and Hausner ratio values under moisture content between 6.59-14.48 g $\mathrm{H}_{2} \mathrm{O} / 100 \mathrm{~g}$ d.s. "Arbol" and "Piquin" chili powders presented the higher capsaicin content, while "Guajillo" and "Mole ranchero" showed the higher carotenoids content. FTIR spectra confirmed the presence of secondary amide, phenolic groups, alkanes, and aliphatic chains that belong to capsaicin structure at specific absorption bands. Microstructure of chili powders presented particles with surface imperfections as cracks and dents, and smooth surface that influence physicalchemical and flowability properties.

Limitations on study/implications: Hight moisture content affect the physical-chemical properties, flowability and microstructure of traditional Mexican chili powders.

Findings/conclusions: Moisture content between 6.59 and $14.48 \mathrm{~g} \mathrm{H}_{2} \mathrm{O} / 100 \mathrm{~g}$ d.s. influences the physicalchemical properties, flowability and microstructure of traditional Mexican chili powders. To improve physicalchemical properties and flowability behavior of chili powders is required that moisture content be lower than $6.59 \mathrm{H}_{2} \mathrm{O} / 100 \mathrm{~g}$ d.s.

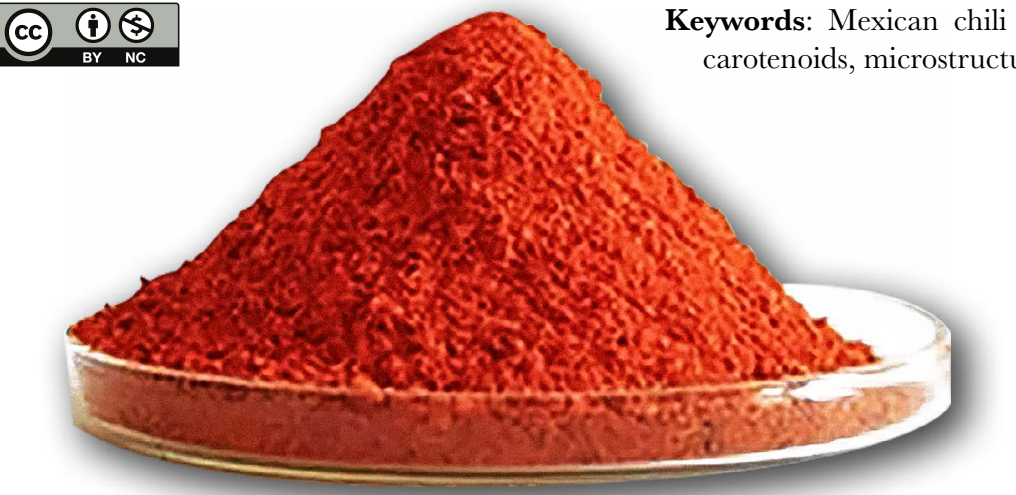




\section{INTRODUCTION}

The chili (Capsicum annuum L.) (Solanaceae) is native of America, is consumed as vegetable, spice, and as source of vitamins $\mathrm{A}, \mathrm{C}$ and $\mathrm{E}$, carotenoids, and capsaicin which produce the characteristic pungency of Capsicum species. The chili in Mexico is usually processed in dried form to conserve its color and flavor. Dehydrated chili is employed in instant soups, frozen pizzas, salad dressings and a great variety of sauces and foods. During the dehydration process, water content and water activity are partially or totally reduced and, consequently, microbial growth and the enzymatic activity are limited, yielding an extended shelf-life of the product, beside of protect the bioactive compounds and conserve the physical-chemical properties of chili-based products (Domian \& Poszytek, 2005; De Marino et al., 2006; Cisneros-Pineda et al., 2010; Yaldiz et al., 2010; Valdez-Fragoso et al., 2013). Processing and handling of powders have increasingly in the food and pharmaceutical industries. Knowledge of food powder properties has grown to the extent that increases product value, and processes complexity as well as development of new formulations. In this sense, flow properties are very important in many unitary operations which involve powders flowability, such as: pneumatic transport from specific equipment or silo, mixing and packaging. Flowability is affected by many factors such as particle size, shape, density, chemical composition, and moisture content. Powder properties are commonly determined under loading conditions of gravity, by means of angle of repose, standardized flow rate, aerated and tapped bulk density values, beside of Carr Index and Hausner ratio (Zou and Brusewitz, 2002; Thalberg et al., 2004; Cavalcante-Alves et al., 2008; Emery et al., 2009; Perea-Flores et al., 2010). Density is a basic property for materials and industrial processes characterization, storage selection, packaging, and distribution conditions. Aerated and tapped bulk density are generally used to characterize final products obtained by mean of milling or drying, weight estimation to fill containers and to relate the powder density before and after compression (Abdullah \& Geldart, 1999; Barbosa-Cánovas et al., 2005; Fitzpatrick, 2005). Angle of repose is the steepest angle of descent relative to the horizontal plane to which a material can be piled without slumping. This parameter indicates that interparticulate friction has been used to characterize flow behaviour of the powder and granular materials respect to flowability (Frączec et al., 2007; Xinde et al., 2007; Ileleji \& Zhou, 2008). Powder compressibility is commonly used as a flowability indicator and is often expressed using the Hausner ratio, by means of aerated/tapped bulk density ratio and is appropriate to estimate cohesion in powders. In addition, the Carr index is other compressibility indicator to evaluate powder flow properties (Thalberg et al., 2004; Barbosa-Cánovas \& Juliano, 2005; Cavalvante-Alves et al., 2008; Khandai et al., 2014). Nowadays, the study of food powder microstructure is relevant and has grown in parallel with the development of microscopy and image processing techniques (Wang, 2006; Pérez-Alonso et al., 2009). Some methods analyze food microstructure and correlate it with chemical composition and properties: Light Microscopy (LM), Scanning Electron Microscopy (SEM), and Confocal Laser Scanning Microscopy (CLSM), covering the whole dimensional scale from microstructural to macrostructural level (Kim et al., 2009; Perea-Flores et al., 2010). Therefore, the aim of this research was evaluating the physical- 
chemical properties and characterize the microstructure of four traditional Mexican chili powders: "Árbol", "Guajillo", "Piquin" and "Mole ranchero" (Figure 1).

\section{MATERIALS AND METHODS}

Samples: Four samples of traditional Mexican chili powders: "Arbol", "Guajillo", "Piquin" and "Mole ranchero" (Ancho chili), were purchased in a local market from Toluca, State of Mexico, Mexico. Capsicum oleoresin standard was provided by Sensient Colors Company, S.A. de G.V. (Lerma, State of Mexico, Mexico). All reagents used in the study were purchased from Sigma-Aldrich, S.A. de C.V. (Toluca, State of Mexico, Mexico).

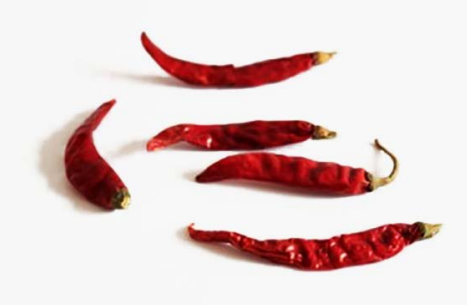

Arbol Chilli

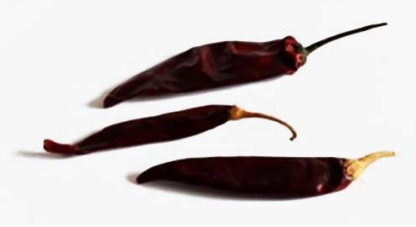

Guajillo Chilli
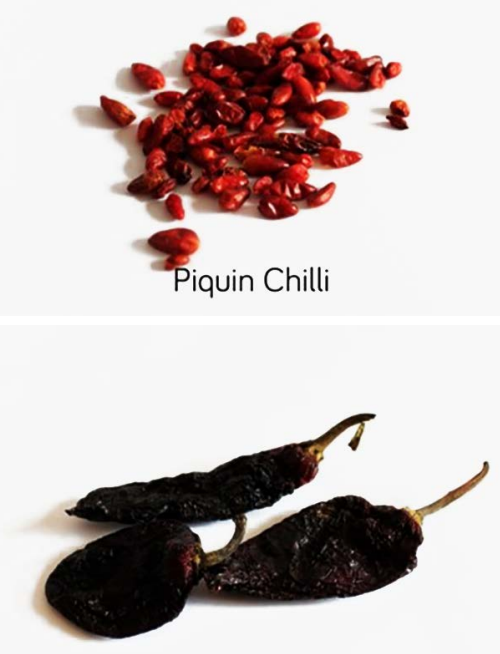

Ancho Chilli
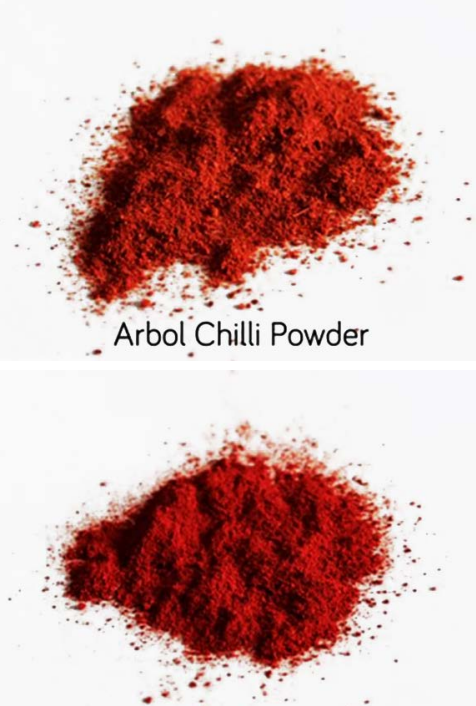

Guajillo Chilli Powder

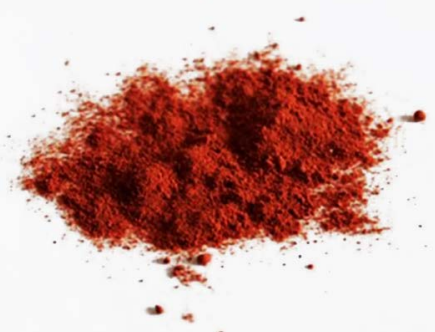

Piquin Chilli Powder

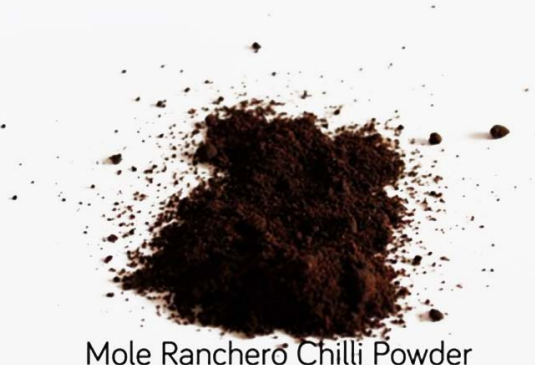

Figure 1. Traditional mexican chili powders (Capsicum annuum L.) Source: Created by the authors. 
Aerated and tapped bulk density: samples were gently poured into a $100 \mathrm{~mL}$ graduate cylinder. Aerated bulk density $\left(\rho_{a}\right)$ was calculated as the ratio between the weights (g) of the sample contained in the cylinder and the filled volume $(100 \mathrm{~mL})$. Tapped bulk density $\left(\rho_{b}\right)$ was estimated by tapping the cylinder (100 times) until no measurable change in volume was noticed (León-Martínez et al., 2010; Gallo et al., 2011).

Particle size: was determined using a particle size analyzer Malvernsizer 2000 (Malvern Instruments, Ltd., Malvern, Worcetershire, UK). The average particle size was obtained using the software Malvernsizer 5.6 integrated to the equipment (Pérez-Alonso $e t$ al., 2009).

Moisture content: was determined according to AOAC method (2005).

Angle of repose: was determined by pouring a pre-defined mass of $50 \mathrm{~g}$ of chili powder sample through a funnel located at a fixed height on a graph paper flat horizontal surface and measuring powder conical pile height $(h)$ and radius $(r)$ formed. The tangent of the angle of repose is given by the $h / r$ ratio (Gallo et al., 2011).

Carr index and Hauser ratio: were evaluated by means of the relationship between aerated bulk density and tapped bulk density, using equations (1)-(2) (Ganesan et al., 2008; Gallo et al., 2011):

$$
\begin{gathered}
C I \%=\left[\frac{\left(\rho_{b}\right)-\left(\rho_{a}\right)}{\rho_{b}}\right] \times 100 \\
H R=\left[\frac{\left(\rho_{b}\right)}{\left(\rho_{a}\right)}\right]
\end{gathered}
$$

$C I \%$ is the Carr index and $H R$ is the Hausner ratio, $\left(\rho_{a}\right)$ is the aerated bulk density in $\mathrm{g} / \mathrm{mL}$ and $\left(\rho_{b}\right)$ is the tapped bulk density $(\mathrm{g} / \mathrm{mL})$.

Capsaicin content: $0.1 \mathrm{~g}$ of sample and $0.025 \mathrm{~g}$ for capsicum oleoresin standard, were extracted during 4 hours at $25^{\circ} \mathrm{C}$ with $50 \mathrm{~mL}$ of acetone, with a slight modification respect to Hornero \& Mínguez spectrophotometric method (2001). Absorbance was measured in a UV spectrophotometer GENESYS2-UV/visible (Spectronic, Rochester, NY, USA) at $\lambda=460 \mathrm{~nm}$ and using acetone as blank (Hornero \& Mínguez, 2001; Braga \& Oliveira, 2007).

Carotenoids content: determined according to Hornero \& Mínguez (2001) spectrophotometric method with a slight modification. Absorbance measurements were made in a UV spectrophotometer GENESYS 2-UV/visible (Spectronic, Rochester, NY, USA) at $\lambda=472$ and $508 \mathrm{~nm}$. To obtain isochromic fraction and total carotenoids content, the following equations (3)-(5) were used:

$$
C R=\left[\frac{\left(A_{508}\right) \times(2144)-\left(A_{472}\right) \times(403.3)}{270.9}\right](\mu g / m L)
$$




$$
\begin{gathered}
C Y=\left[\frac{\left(A_{472}\right) \times(1724.3)-\left(A_{508}\right) \times(403.3)}{270.9}\right](\mu g / m L) \\
C T=C R+C Y(\mu g / m L)
\end{gathered}
$$

$A_{508}$ is the absorbance of samples at $\lambda=508 \mathrm{~nm}, A_{472}$ is the absorbance of samples at $\lambda=472$ nm of the samples $C R$ represents the red isochromatic fraction content, $C Y$ represents the yellow isochromatic fraction content, and $C T$ represents the total carotenoids content.

Extractable color (ASTA units): were determined according to ASTA 20.1 method. The absorbance of each sample was measured against acetone blank at $\lambda=460 \mathrm{~nm}$ in a UV spectrophotometer GENESYS 2-UV/visible (Spectronic, Rochester, NY, USA). Extractable colour values were expressed in ASTA units and calculated by the Ec (6) (Topuz et al., 2009; Rascón et al., 2011):

$$
\text { ASTA units }=\left[\frac{A \times 164 \times I f}{W_{\text {sample }}}\right]
$$

$A$ is the absorbance of sample at $I=460 \mathrm{~nm}$, If is the deviation factor of the spectrophotometer and $W$ is the sample weight $(\mathrm{g})$ in dry basis.

FTIR Spectroscopy: chemical groups associated to capsaicin and carotenoids were identified by FTIR Spectroscopy, using a Micro-Raman Spectrometer (Lab RAM HR800, Horiba Jobin-Yvon, France) coupled to Fourier Transform Infrared Spectroscopy and a Charge Detector, using an Attenuated Total Reflectance objective (ATR-FTIR) with 36x magnification. Spectra were acquired from 4000 to $400 \mathrm{~cm}^{-1}$ and the baseline spectra adjusted with Origin Pro 8.0 software (Origin Lab Corporation, MA, USA) and compared with capsicum oleoresin standard spectrum.

Scanning Electron Microscopy (SEM): microstructure was characterized using a Dual Beam SEM Microscope model (Quanta 3D, FEG, FEI, Holland). Samples were fixed with double-sided carbon adhesive tape on aluminum stubs and directly observed at $15 \mathrm{kV}$, using a low vacuum secondary electron detector to minimize charging. Micrographs were acquired at 250x and 1000x (Quintanilla-Carvajal et al., 2011; De la Rosa-Millán et al., 2014).

Confocal Laser Scanning Microscopy (GLSM): samples were characterized with CLSM equipment (CLSM 710 NLO, Carl Zeiss, Germany) using a plan-Apochromat 40x/1.3 oil DIC M27 objective, and were excited at $\lambda=405,488$ and $561 \mathrm{~nm}$. Autofluorescence intensity measurement was performed using the software ZEN coupled to the equipment. Were acquired 3D images of samples ( $\mathrm{x}, \mathrm{y}$ and $\mathrm{z})$ in sections of different focal planes (Quintanilla-Carvajal et al., 2011). 
Statistical analysis: ANOVA and Tukey test were performed to evaluate the significant difference between samples at $95 \%$ of confidence level.

\section{RESULTS AND DISGUSION}

Aerated and tapped bulk density: Density is influenced by particle size; at lower particle size, aerated and tapped bulk density increase because there is more surface contact area available for cohesive and frictional forces to resist flowability and the influence of compaction capability and the shape of particles of chili powders, this behavior is showed in "Guajillo", "Piquin" and "Mole ranchero", meanwhile "Arbol" chili exhibit the higher particle size and the lower density values (Table 1). "Mole ranchero" showed the highest aerated and tapped bulk density values. In the other hand, particle size and shape influence the aerated and tapped bulk densitiy due to the compaction capability that powders present by the presence of surface imperfections as cracks and dents that "Arbol", "Guajillo" and "Piquin" presented and by the smooth surfaces that "Mole Ranchero" presented.

Angle of repose: to classify flowability of powders, Gallo et al. (2013), give a classification between $25^{\circ}$ and $30^{\circ}$ as an excellent flowing and greater than $31^{\circ}$ as poor flowing, while Santomaso et al. (2003), give values between $30^{\circ}$ and $45^{\circ}$ to powders that free flowing and values between $45^{\circ}$ and $60^{\circ}$ to powders fairly to free flowing. "Arbol"chilli", "Piquin" and "Mole ranchero" showed a behavior near to free flowing, while "Guajillo" showed a behavior fairly to free flowing, and these values indicate that chili powders are cohesive and tend to form agglomerates (Table 1, Figure 2). Angle of repose involves a compaction and tapping process, which produce a little deformation of agglomerates and reflect the surface properties, including the degree of agglomerates, particle morphology, friction, and cohesive forces between particles, whereby the angle of repose could be used as a flowability index of chili powders. Figure 2 illustrates the flow pattern of the conical pile formed to measure angle of repose from traditional mexican chili powders.

Carr index and Hausner ratio: these parameters express the compaction and compressibility capabilities related to frictional forces between powder particles. Gallo $e t$ al. (2013) give Carr index values between 10 and 25 to identify powders with excellent and acceptable flowability. Santomaso et al. (2003) give Hausner ratio values between 1 and 1.25 to identify powders with excellent and near to free flowing, while values between 1.25 and

Table 1. Physical-chemical properties of traditional mexican chili powders.

\begin{tabular}{l|c|c|c|c|c|c|c}
\multicolumn{1}{c|}{ Samples } & $\begin{array}{c}\text { Moisture } \\
\text { content } \\
(\mathbf{g H} \mathbf{O} / \mathbf{1 0 0} \\
\mathbf{d . s})\end{array}$ & $\begin{array}{c}\text { Particle } \\
\mathbf{s i z e} \\
\mathbf{d}_{\mathbf{4}, 3}(\mu \mathbf{m})\end{array}$ & $\begin{array}{c}\text { Aerated bulk } \\
\mathbf{d e n s i t y} \\
\left(\rho_{\mathbf{a}}\right)(\mathbf{g} / \mathbf{m L})\end{array}$ & $\begin{array}{c}\text { Tapped bulk } \\
\mathbf{d e n s i t y}\left(\rho_{\mathbf{b}}\right) \\
(\mathbf{g} / \mathbf{m L})\end{array}$ & $\begin{array}{c}\text { Carr } \\
\text { index } \\
(\mathbf{a u})^{*}\end{array}$ & $\begin{array}{c}\text { Angle of } \\
\text { repose } \alpha_{\mathbf{r}} \\
\left({ }^{\circ}\right)\end{array}$ & $\begin{array}{c}\text { Hausner } \\
\text { ratio } \\
(\mathbf{a u})^{*}\end{array}$ \\
\hline Arbol chilli & $7.92 \pm 0.10^{\mathrm{a}}$ & $643.68 \pm 0.00^{\mathrm{a}}$ & $0.40 \pm 0.00^{\mathrm{a}}$ & $0.57 \pm 0.01^{\mathrm{a}}$ & $29.82 \pm 0.95^{\mathrm{a}}$ & $37.9 \pm 0.09^{\mathrm{a}}$ & $1.43 \pm 0.01^{\mathrm{a}}$ \\
\hline Guajillo chilli & $9.58 \pm 0.10^{\mathrm{b}}$ & $330.99 \pm 0.00^{\mathrm{b}}$ & $0.42 \pm 0.02^{\mathrm{b}}$ & $0.61 \pm 0.00^{\mathrm{b}}$ & $31.14 \pm 0.00^{\mathrm{b}}$ & $46.68 \pm 0.08^{\mathrm{b}}$ & $1.45 \pm 0.00^{\mathrm{b}}$ \\
\hline Piquin chilli & $6.59 \pm 0.10^{\mathrm{c}}$ & $247.49 \pm 0.00^{\mathrm{c}}$ & $0.44 \pm 0.02^{\mathrm{c}}$ & $0.69 \pm 0.01^{\mathrm{c}}$ & $36.23 \pm 1.00^{\mathrm{c}}$ & $44.31 \pm 0.40^{\mathrm{c}}$ & $1.56 \pm 0.02^{\mathrm{c}}$ \\
\hline Mole ranchero & $14.48 \pm 0.10^{\mathrm{d}}$ & $342.53 \pm 0.00^{\mathrm{d}}$ & $0.52 \pm 0.05^{\mathrm{d}}$ & $0.77 \pm 0.01^{\mathrm{d}}$ & $32.46 \pm 0.01^{\mathrm{d}}$ & $41.20 \pm 0.04^{\mathrm{d}}$ & $1.48 \pm 0.01^{\mathrm{d}}$ \\
\hline
\end{tabular}

$*(\mathrm{au})$ : adimensional units.

The values with different letter in the same column present a significant difference between every sample. 


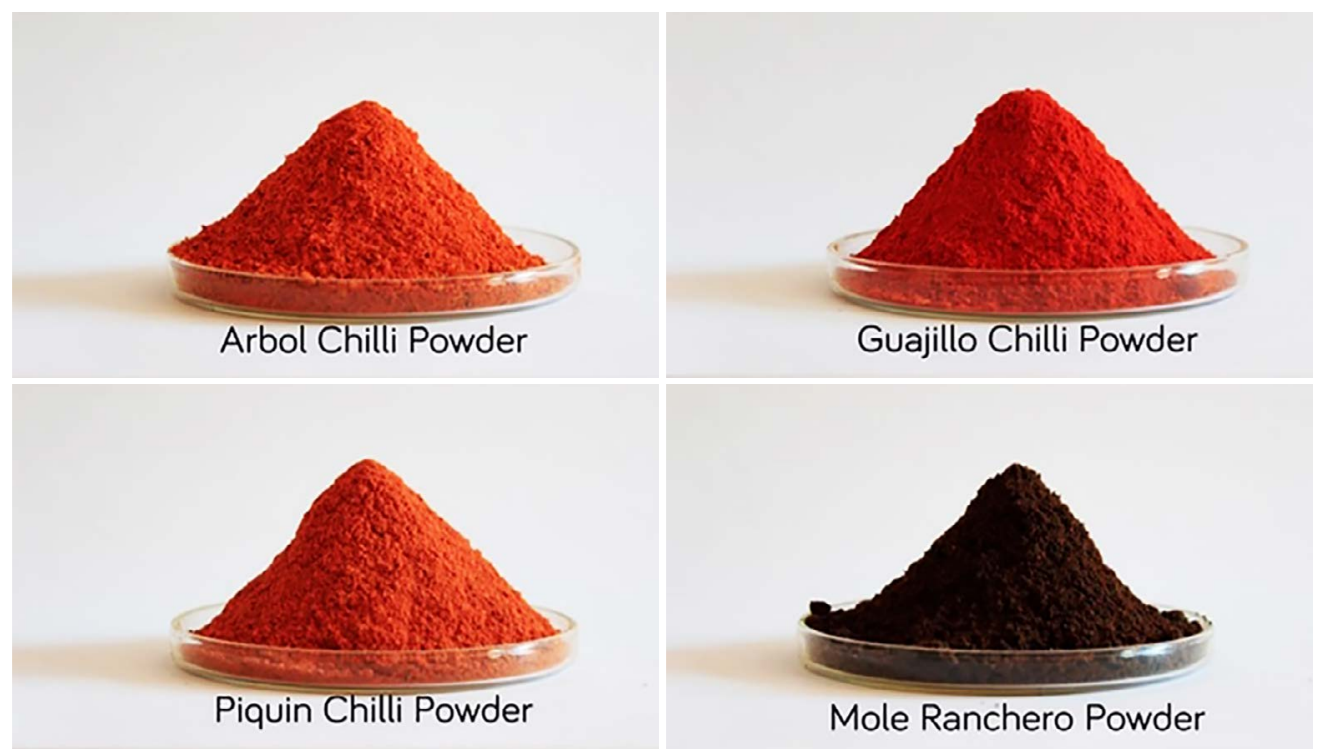

Figure 2. Angle of repose evaluated from traditional mexican chilli powders (Capsicum annuum L.) Source: created by the authors

1.4 indicate a behavior fairly to free-flowing powders. "Arbol", "Guajillo", "Piquin" and "Mole ranchero" showed a cohesive behavior fairly to free flow with significant difference between Carr index and Hausner ratio values. "Mole ranchero" is a very cohesive powder due to its higher moisture content of $14 \mathrm{gH}_{2} \mathrm{O} / 100 \mathrm{~g}$ d.s. respect to "Arbol", "Guajillo" and "Piquin" chili at moisture contents of 7.92, 9.58 and $6.59 \mathrm{~g} \mathrm{H}_{2} \mathrm{O} / 100 \mathrm{~g}$ d.s. respectively.

Chemical group's composition: FTIR spectra of chili powders presented in Figure 3, showed a characteristic band of absorption of axial deformation of $\mathrm{C}-\mathrm{H}$ aromatic and aliphatic chains at $2900 \mathrm{~cm}^{-1}$, a band of asymmetric and symmetric axial deformation of C-O-C bonds at $1690 \mathrm{~cm}^{-1}$, a band at $1652 \mathrm{~cm}^{-1}$ associated to a secondary amide, a band of axial deformation of $\mathrm{C}=\mathrm{C}$ of the double ring at $1590 \mathrm{~cm}^{-1}$, and a band of absorption of axial deformation of $\mathrm{C}=\mathrm{O}$ bonds at $1158 \mathrm{~cm}^{-1}$ related to a phenolic group. These results are agreed with capsicum oleoresin standard spectra and with the FTIR spectra reported for chili samples by Toshimasa et al. (2003) and De Marino et al. (2006), which confirms the chemical groups related to capsaicin molecule and carotenoids structure.

Capsaicin and carotenoids content: results are shown in Table 2. "Piquin" and "Arbol" presented the higher capsaicin content, meanwhile "Guajillo" and "Mole ranchero" showed the lower capsaicin content, respect to the capsicum oleoresin standard content. In the other hand, "Guajillo" and "Mole ranchero" presented the higher carotenoids content respect to the capsicum oleoresin standard content. "Guajillo" showed the higher carotenoids content and a lower capsaicin content, while "Piquin chili" presented the higher capsaicin content and the lower carotenoids content. "Guajillo" and "Mole Ranchero" presented the highest red fraction, yellow fraction, and total fraction of carotenoids, and the lowest capsaicin content. Experimental values obtained are in accordance with the values reported in chili samples by Rodríguez-Maturino et al. (2012). 


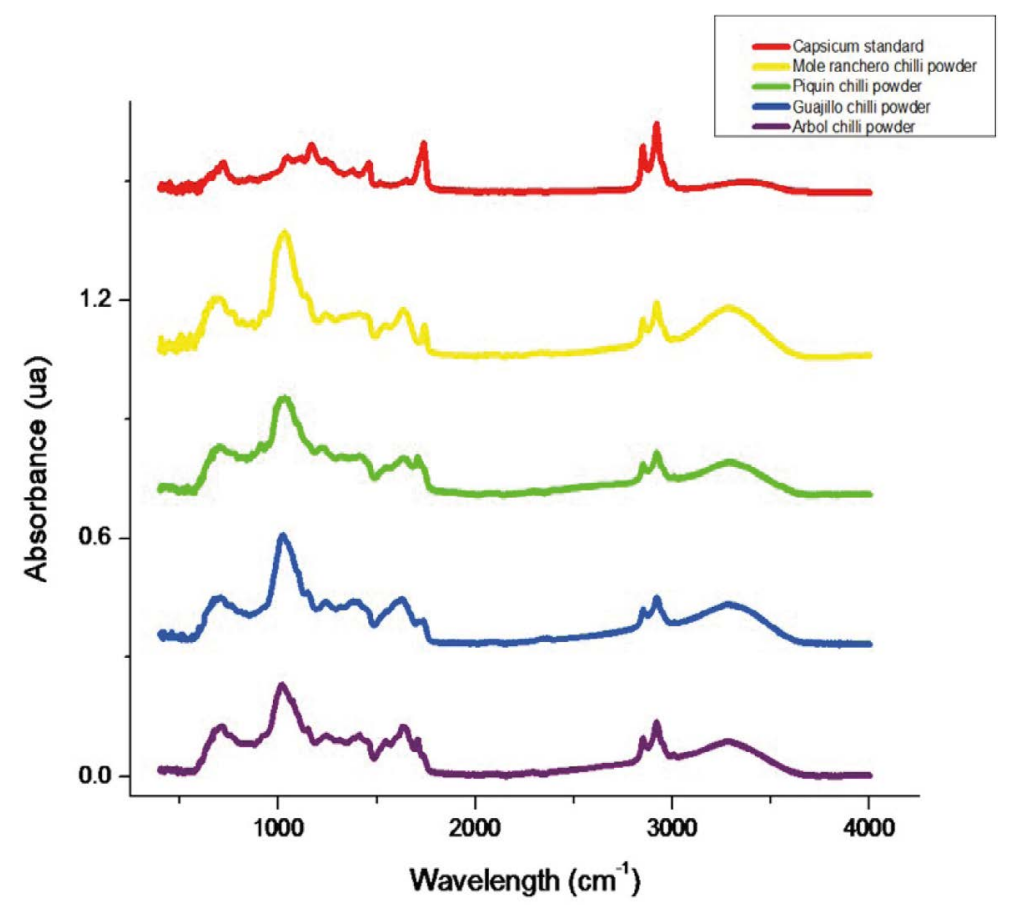

Figure 3. FTIR spectra of traditional mexican chilli powders (Capsicum annuum L.) Source: created by the authors.

Extractable color (ASTA units): "Guajillo" and "Mole Ranchero" showed the higher extractable color value, while "Arbol" and "Piquin" showed the lower extractable color values. All samples were compared with capsicum oleoresin standard extractable color values (Table 2). The significant difference of extractable color in the samples is related to the Red (CR) and Yellow (CY) fractions of carotenoids, where "Guajillo" and "Mole Ranchero" presented the higher red and yellow fractions of carotenoids, while "Arbol" and "Piquin" presented the lower red and yellow fraction (CR). Results obtained are agreed with the values reported by Rodríguez-Maturino et al. (2012).

Microstructure: "Arbol", "Guajillo" and "Piquin" presented particles with surface imperfections as cracks and dents, while "Mole Ranchero" showed a smooth surface, which

Table 2. Capsaicin, carotenoids, and color content of traditional mexican chilli powders.

\begin{tabular}{l|c|c|c|c|c}
\hline \multicolumn{1}{c|}{ Parameters } & Capsaicin & \multicolumn{3}{|c|}{ Carotenoids } & Color \\
\hline \multicolumn{1}{c|}{ Samples } & $\begin{array}{c}\text { Concentration } \\
(\mathbf{m g} / \mathbf{L})\end{array}$ & $\begin{array}{c}\text { Red fraction } \\
\text { CR }(\mu \mathbf{g} / \mathbf{m L})\end{array}$ & $\begin{array}{c}\text { Yellow fraction } \\
\text { GY }(\mu \mathbf{g} / \mathbf{m L})\end{array}$ & $\begin{array}{c}\text { Total fraction } \\
\text { CT }=\mathbf{C R}+\mathbf{G Y} \\
(\mu \mathbf{g} / \mathbf{m L})\end{array}$ & $\begin{array}{c}\text { ASTA } \\
\text { units }(\mathbf{a u})^{*}\end{array}$ \\
\hline Arbol chilli & $97.28 \pm 0.18^{\mathrm{a}}$ & $197.73 \pm 0.00^{\mathrm{a}}$ & $260.10 \pm 0.00^{\mathrm{a}}$ & $457.84 \pm 0.00^{\mathrm{a}}$ & $279.48 \pm 0.00^{\mathrm{a}}$ \\
\hline Guajillo chilli & $18.67 \pm 0.00^{\mathrm{b}}$ & $846.44 \pm 0.00^{\mathrm{b}}$ & $1324.71 \pm 0.00^{\mathrm{b}}$ & $2171.15 \pm 0.00^{\mathrm{b}}$ & $1256.92 \pm 0.01^{\mathrm{b}}$ \\
\hline Piquin chilli & $121.95 \pm 0.00^{\mathrm{c}}$ & $117.07 \pm 0.00^{\mathrm{c}}$ & $155.26 \pm 0.00^{\mathrm{c}}$ & $272.33 \pm 0.00^{\mathrm{c}}$ & $192.30 \pm 0.00^{\mathrm{c}}$ \\
\hline Mole ranchero & $46.23 \pm 0.00^{\mathrm{d}}$ & $316.94 \pm 0.01^{\mathrm{d}}$ & $427.43 \pm 0.01^{\mathrm{d}}$ & $744.37 \pm 0.01^{\mathrm{d}}$ & $476.41 \pm 0.01^{\mathrm{d}}$ \\
\hline Capsicum std & $136.38 \pm 0.00^{\mathrm{e}}$ & $794.14 \pm 0.00^{\mathrm{e}}$ & $1477.24 \pm 0.00^{\mathrm{e}}$ & $2271.38 \pm 0.00^{\mathrm{e}}$ & $1405.64 \pm 0.00^{\mathrm{e}}$ \\
\hline
\end{tabular}

*(au): adimensional units

The values with different letter in the same column present a significant difference between every sample. 
can be observed in Figure 4. The 3D CLSM images showed the autofluorescence (green and red) identified in traditional Mexican chili powders, which is related to capsaicin and carotenoids compounds (Vazquez-Gutiérrez et al., 2011), where the red fluorescence is associated to capsaicin content at $\lambda=460 \mathrm{~nm}$.

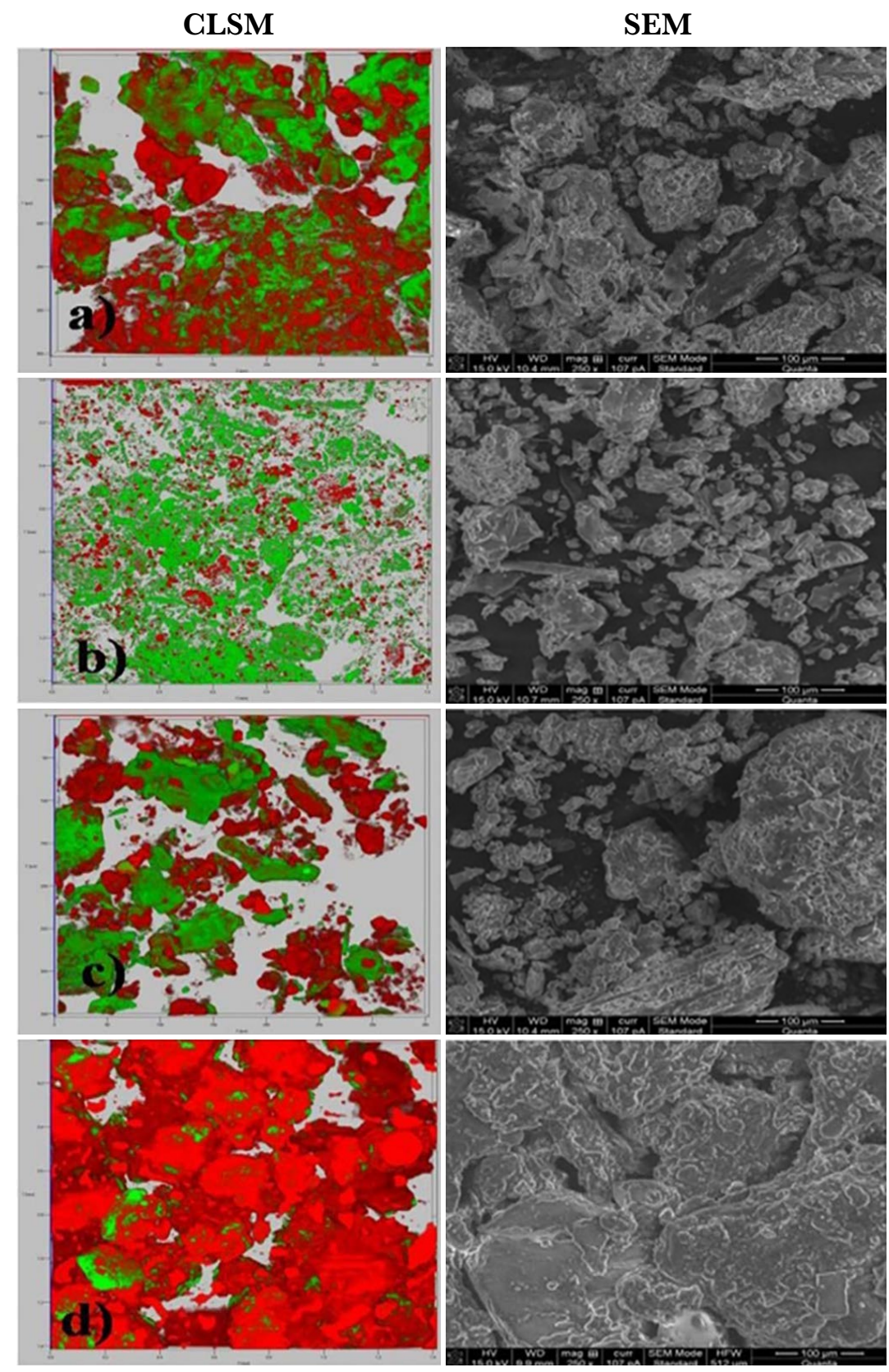

Figure 4. Confocal Laser Scanning Microscopy (CLSM) and Scanning Electron Microscopy (SEM) micrographs of traditional mexican chilli powders. a) Arbol chilli, b) Guajillo chilli, c) Piquin Chilli and c) Mole ranchero. Source: created by the authors. 


\section{GONGLUSIONS}

"Arbol", "Guajillo", "Piquin" and "Mole Ranchero" presented a cohesive behavior respect to its physical-chemical properties and flowability. "Arbol" and "Piquin" present the higher capsaicin content while "Guajillo" and "Mole ranchero" showed the higher carotenoids content. FTIR spectra confirmed the presence of secondary amide, phenolic groups, alkanes, and aliphatic chains that belong to capsaicin structure from chili. Microstructure of chili powders presented particles with surface imperfections as cracks and dents, and smooth surface that influence physical-chemical properties. Moisture content between 6.59 and $14.48 \mathrm{~g} \mathrm{H}_{2} \mathrm{O} / 100 \mathrm{~g}$ d.s. influences the physical-chemical properties, flowability behavior and microstructure of traditional Mexican chili powders. To improve physical-chemical properties and flowability behavior of chili powders is required that moisture content be lower than $6.59 \mathrm{~g} \mathrm{H}_{2} \mathrm{O} / 100 \mathrm{~g}$ d.s.

\section{REFERENGES}

Abdullah, E.C. \& Geldart, D. (1999). The use of bulk density measurements as flowability indicators. Powder Technology 102, 151-165. https://doi.org/10.1016/S0032-5910(98)00208-3

AOAC. (2005). Official methods of analysis of AOAC International (16th ed.). Gaythersburg, USA.

Barbosa-Cánovas, G.V. \& Juliano, P. (2005). Physical and chemical properties of food powders. In C. Onwulata (Ed.), Encapsulated and powdered foods, (pp. 39-71). Taylor \& Francis Inc.

Barbosa-Cánovas, G.V., Ortega-Rivas, E., Juliano, P. \& Yan, H. (2005). Bulk properties. In G.V. BarbosaCánovas (Ed). Food Powders Physical Properties, Processing, and Functionality, (pp. 55-64). Kluwer Academic Plenum Publishers.

Braga, G. K. \& Oliveira, P. W. (2007). Manufacturing drug loaded chitosan microspheres by spray drying: Development, characterization, and potential use in dentistry. Drying Technology 25, 303-310. https:// doi.org/10.1080/07373930601119672

Cavalcante-Alves, G.M., Araujo-Rolim, L., Rolim-Neto, P.J., Lima-Leite, A.C., Brondani, D.J., Morais de Mederos, F.P., Bieber, L.W. \& Bezerra-Mendoza, F.J. (2008). Purificação e caracterização da $\beta$ lapachone e estudo de estabilidade dos cristais em diferentes condições de armazenamento. Quimica Nova 31(2), 413-416. https://doi.org/10.1590/S0100-40422008000200039

Cisneros-Pineda, O., Torres-Tapia, L.W., Gutiérrez-Pacheco, L.C., Contreras-Martín, F., González-Estrada, T. \& Peraza-Sánchez, S. R. (2010). Capsaicinoids quantification in chili peppers cultivated in the state of Yucatan, Mexico. Food Chemistry 104, 1755-1760. https://doi.org/10.1016/j.foodchem.2006.10.076

De Marino, S., Borbone, N., Gala, F., Zollo, F., Fico, G., Pagiotti, R., \& Iorizzi, M. (2006). New Constituents of Sweet Capsicum annuum L. Fruits and Evaluation of Their Biological Activity. Journal of Agricultural and Food Chemistry 54, 7508-7516. https://doi.org/10.1021/j1061404z

De la Rosa-Millán, J., Agama-Acevedo, E., Osorio-Díaz, P. \& Bello-Pérez, L.A. (2014). Effect of cooking, annealing and storage on starch digestibility and physicochemical characteristics of unripe banana flour. Revista Mexicana de Ingeniería Química 13(1), 151-163.

Domian, E. \& Poszytek, K. (2005). Wheat flour flowability as affected by water activity, storage time and consolidation. International Agrophysics 19, 119-124.

Emery, E., Oliver, J., Pugsley, T., Sharma, J. \& Zhou, J. (2009). Flowability of moist pharmaceutical powders. Powder Technology 189, 409-415. https://doi.org/10.1016/j.powtec.2008.06.017

Fitzpatrick, J.J. (2005). Food powder flowability. In G. Onwulata (Ed.), Encapsulated and powdered foods, (pp. 247-260). Boca Raton: Taylor \& Francis Inc.

Frączec, J., Zlobecki, A. \& Zemanek, J. (2007). Assesment of Angle of repose of granular plant material using computer image analysis. Journal of Food Engineering 83, 17-22. https://doi.org/10.1016/j. jfoodeng.2006.11.028

Gallo, L., Llabot, J.M., Alemandi, D., Bucalá, V. \& Piña, J. (2011). Influence of spray-drying operating conditions on Rhamnus purshiana (Cáscara sagrada) extract powder physical properties. Powder Technology 208, 205-214. https://doi.org/10.1016/j.powtec.2010.12.021

Gallo, L., Piña, J., Bucalá, V., Allemandi, D. \& Ramírez-Rigo, M.V. (2013). Development of a modified release hydrophilic matrix system of a plant extract based on co-spray-dried powders. Powder Technology 241, 252-262. https://doi.org/10.1016/j.powtec.2013.03.011 
Ganesan, V, Rosentrater, K.A. \& Muthukumarappan, K. (2008). Flowability and handling characteristics of bulk solids and powders - a review with implications for DDGS. Biosystems Engineering 1(1), 425-435. https://doi.org/10.1016/j.biosystemseng.2008.09.008

Hornero, D. \& Mínguez, M. I. (2001). Rapid spectrophotometric determination of red and yellow isochromic carotenoid fractions in paprika and red pepper oleoresins. Journal of Agricultural and Food Chemistry 49, 3584-3588. https://doi.org/10.1021/jf0104001

Ileleji, K.E. \& Zhou, B. (2008). The angle of repose of bulk corn stover particles. Powder Technology 187, 110 118. https://doi.org/10.1016/j.powtec.2008.01.029

Khandai, M., Chakraborty, S. \& Ghosh, A.K. (2014). Critical analysis of algino-carbopol multiparticulate system for the improvement of flowability, compressibility and tableting properties of a poor flow drug. Powder Technology 253, 223-229. https://doi.org/10.1016/j.powtec.2013.11.026

Kim, E., Chen, X.D \& Pearce, D. (2009). Surface composition of industrial spray-dried milk powders. Changes in the surface composition during long-term storage. Journal of Food Engineering 94, 182-191. https:// doi.org/10.1016/j.jfoodeng.2008.12.001

León-Martínez, F. M., Méndez-Lagunas, L.L. \& Rodríguez-Ramírez, J. (2010). Spray drying of nopal mucilage (Opuntia ficus indica): Effects on powder properties and characterization. Carbohydrate Polymers 81(4), 864-870. https://doi.org/10.1016/j.carbpol.2010.03.061

Perea Flores, M.J., Chanona Pérez, J.J., Terres Rojas, E., Calderón Domínguez, G., Garibay Febles, V., Alamilla Beltrán, L., \& Gutiérrez López, G.F. (2010). Microstructure characterization of milk powders and their relationship with rehydration properties. In M.W. Woo, A.S. Mujumdar \& W.R.W Dau (Eds.), Spray Drying Technology (pp. 197-219). Singapore: Transport Processes Research.

Pérez-Alonso C., Fabela-Morón M. F, Guadarrama-Lezama A. Y., Barrera-Pichardo J. F., Alamilla-Beltrán L. y Rodríguez-Huezo M.E. (2009). Interrelationship Between the Structural Features and Rehydration Properties of Spray Dried Manzano Chilli Sauce Microcapsules. Revista Mexicana de Ingeniería Química $8(2), 187-196$.

Quintanilla-Carvajal, M. X., Meraz-Torres, L.S., Alamilla-Beltrán, L., Chanona-Pérez, J.J. Terres-Rojas, E., Hernández-Sánchez, H., Jiménez-Aparicio, A.R. \& Gutiérrez-López, G.F. (2011). Morphometric characterization of spray-dried microcapsules before and after $\alpha$-tocopherol extraction. Revista Mexicana de Ingeniería Química 10 (2), 301-312.

Rascón, M.P., Beristain, C.I., García, H.S. \& Salgado, M.A. (2011). Carotenoid retention and storage stability of spray-dried encapsulated paprika oleoresin using gum Arabic and Soy protein isolate as wall materials. LWT-Food Science and Technology 44, 549-557. https://doi.org/10.1016/j.lwt.2010.08.021

Rodríguez-Maturino, A., Valenzuela-Solorio, A., Troncoso-Rojas, R., González-Mendoza, D., Grimaldo Juarez, O., Aviles-Marin, M. \& Cervantes-Diaz, L. (2012). Antioxidant activity and bioactive compounds of Chiltepin (Capsicum annuum var. glabriusculum) and Habanero (Capsicum chinense): A comparative study. Journal of Medicinal Plants Research 6(9), 1758-1763. https://doi.org/10.5897/ JMPR11.1576

Santomaso, A., Lazzaro, P. \& Canu, P. (2003). Powder flowability and density ratios: the impact of granules packing. Chemical Engineering Science 58, 2857-2874. https://doi.org/10.1016/S00092509(03)00137-4

Thalberg, K., Lindholm, D. \& Axelsson, A. (2004). Comparison of different flowability tests for powders for inhalation. Powder Technology 146, 206-213. https://doi.org/10.1016/j.powtec.2004.08.003

Topuz, A., Feng, H. \& Kushad, M. (2009). The effect of drying method and storage on color characteristics of paprika. LWT-Food Science and Technology 42, 1667-1673. https://doi.org/10.1016/j.lwt.2009.05.014

Toshimasa, O., Yoshihisa, T., Kentarou, K. \& Izumi, Y. (2003). Antioxidant Activity of a New Capsaicin Derivative from Capsicum annuum. Natural Products 66, 1094-1096. https://doi.org/10.1021/ np020465y

Valdez-Fragoso, A., Soto-Caballero, M.C., Soria-Hernández, C.G., Valiente-Banuet, J.I., Welti-Chanes \& Mújica-Paz, H. (2013). Pickling variables effect on mass transfer, stability and quality parameters of piquin pepper. Revista Mexicana de Ingeniería Química 12(1), 1-10.

Vázquez-Gutiérrez, J.L., Quiles, A., Hernando, I. \& Pérez-Munuera, I. (2011). Changes in the microstructure and location of some bioactive compounds in persimmons treated by high hydrostatic pressure. Postharvest Biology and Technology 61, 137-144. https://doi.org/10.1016/j.postharvbio.2011.03.008

Wang, W. (2006). Size and shape measure of particles by image analysis. Lecture Notes in Computer Science 40, 253-262. https://doi.org/10.1007/11774938_20

Xinde, X., Shanjing, Y., Ning, H. \& Bin, S. (2007). Measurements and influence factors of the flowability of microcapsules with high-content $\beta$-Carotene. Chinese Journal of Chemical Engineering 15(4), 579-585. https://doi.org/10.1016/S1004-9541(07)60127-X 
Yaldiz, G., Ozguven, M. \& Sekeroglu, N. (2010). Variation in capsaicin contents of different Capsicum species and lines by varying drying parameters. Industrial Crops and Products 32, 434-438. https://doi. org/10.1016/j.indcrop.2010.06.013

Zou, Y. \& Brusewitz, G.H. (2002). Flowability of uncompacted marigold powder as affected by moisture content. Journal of Food Engineering 55, 165-171. https://doi.org/10.1016/S0260-8774(02)00060-2

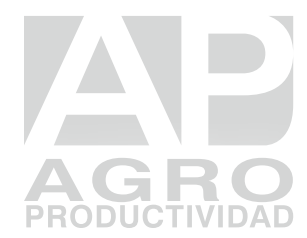

